\title{
MECHANICAL PROPERTIES OF GEOPOLYMER CONCRETE WITH COMBINED MINERAL ADMIXTURES
}

\author{
Y. Naveen Kumar \\ Associate Professor, Department of Civil Engineering, \\ Siddhartha institute of engineering \& technology, Vinobha Nagar, Ibrahimpatnam Hyderabad (TS) \\ Dr. B. Dean Kumar \\ Professor, Department of Civil Engineering, \\ JNTU. College of Engineering, Kukatpalli, Hyderabad (TS) \\ Dr.B.L.P Swami \\ Professor and Co-coordinator, Research and Consultancy, Department of Civil Engineering \\ Methodist College of Engineering\& Technology, Abids, Hyderabad-500001, (TS)
}

\begin{abstract}
- in the present study, it is aimed to use fly ash, GGBS, silica fume\& metakaoline as full replacement to cement. They contain high amount of silica and alumina, which can be activated with the help of alkaline solution (i.e., NaoH\&Na2Sio3) to produce geo-polymer concrete (GPC). In the present work investigations are carried out to find strength properties of fly ash, GGBS, Silica fume, \&Metakaoline based geo-polymer concrete i.e. (M40) in various percentages (i.e. FA $100 \%+$ GGB0\% + SF 0\% + MK 0\%, FA70\%+GGBS 20\% +SF 5\% + MK $5 \%$,FA50 $\%$ +GGBS40\% + SF 5\% + MK 5\%, FA 30\% + GGBS $60 \%$ + SF 5\% + MK 5\%, FA $10 \%$ + GGBS $80 \%+\mathrm{SF} 5 \%+\mathrm{MK} 5 \%$, ) with constant molarity (i.e.,8M)
\end{abstract}

The specimens prepared with above specification are cured in oven and ambient conditions. Specimens are tested for compressive strength, splitting tensile strength and flexural strength at various ages(i.e. 7 days, 14 days, 28days, 45days) in order to find out effective combination of flyash, GGBS, silica fume \& metakaoline based geo-polymer concrete mix to produce desired strength properties.

Keywords- Flyash, GGBS, Silica Fume, Metakaoline, NaoH, Na2Sio3, polymerization, Molarity, Oven curing, Ambient curing.

\section{INTRODUCTION}

Use of Industrial wastes

Increased awareness regarding the ill-effects of the over exploitation of natural resources, eco-friendly technologies are to be developed for effective management of these resources. Construction industry is one of the major users of the natural resources like cement, sand, rocks, clays and other soils. The increasing unit cost of the usual ingredients of concrete has forced the construction engineer to think of ways and means of reducing the unit cost of its production. At the same time, increased industrial activity in the core sectors like energy, steel and transportation has been responsible for the production of large amounts of wastes like fly ash, blast furnace slag, silica fume, metakaoline and quarry dust with consequent disposal and pollution problem.

\section{Need for geopolymer concrete (GPC)}

The Geopolymer technology was first introduced by Davidovits in 1978 along with the geopolymer binders. His work considerably shows that the adoption of the geopolymer technology could reduce the $\mathrm{CO}_{2}$. Emission caused by cement industries. In 1978, Davidovits proposed that binders could be produced by a polymeric reaction of alkaline liquids with the silicon and the aluminium in source materials of geological origin or by-product materials such as fly ash and rice husk ash. He termed these binders as geopolymers. Palomo et al suggested that pozzolans such as blast furnace slag might be activated using alkaline liquids to form a binder and hence totally replace the use of OPC in concrete. In this scheme, the main contents to be activated are silicon and calcium in the blast furnace slag. In this respect, the geopolymer technology proposed by Davidovits shows considerable promise for application in concrete industry as an alternative binder to the Portland cement and has generated lot of interest among engineers. Fly ash, one of the by-products of thermal power plants, is utilized as pozzolanic material in cement worldwide.

Utilization of flyash, GGBS, Silica fume, Metakaoline 
Fly ash, which is considered as an industrial waste, if utilized to its maximum capacity in the construction industry, provides the benefits of reducing the conventional cement generated carbon dioxide as well as saving precious land from becoming a landfill site. Hence fly ash based geopolymer concretes have been gaining popularity as an ecofriendly construction material and studies are being conducted on its suitability as an alternative to the much popular Portland cement concrete. Ground granulated blast furnace slag (GGBS) is derived from the waste slag of steel factories. It is pozzolonic in nature and it is a very suitable mineral admixture that can be used along with fly ash in geo polymer concrete (GPC) replacing OPC completely.Metakaolin is a dehydroxylated form of the clay mineral kaolinite. Rocks that are rich in kaolinite are known as china clay or kaolin, traditionally used in the manufacture of porcelain. The particle size of metakaolin is smaller than cement particles, but not as fine as silica fume. Silica fume, also known as micro silica, is an amorphous (noncrystalline) polymorph of silicon dioxide, silica. It is an ultrafine powder collected as a by-product of the silicon and ferrosilicon alloy production and consists of spherical particles with an average particle diameter of $150 \mathrm{~mm}$. The main field of application is as pozzolanic material for high performance concrete.

\section{Polymerization}

The Polymerization process involves a substantially fast chemical reaction under alkaline conditions on $\mathrm{Si}-\mathrm{Al}$ minerals, resulting in a three-dimensional polymeric chain and ring structure consisting of Si-O-Al-O bonds. The formed gel product contains alkaline captions which compensate for the deficit charges associated with the aluminium-for-silicon substitution. An intermediate, aluminium -rich phase is first formed which then gives way to a more stable, silicon rich three-dimensional get product of form Q4(nil), which is dependent upon curing condition and activator type. The slow growth of crystalline structures become evident as the nuclei of the polymerized gel reaches critical size. The matrix crystalinity is relative to the rate by which precipitation occurs: fast reactions between alkali and ash do not allow time for growth of a wells structured crystalline environment (respective of typical zeolites). Therefore, most hardened geopolymer concretes are referred to as zeolitic precursors rather than actual zeolite. The final products geopolymerization is an amorphous, semicrystalline cementations material.

\section{Details of present experimental investigation}

In the present work investigations are carried out to find strength properties of fly ash, GGBS, Silica fume, \& Metakaoline based geo-polymer concrete i.e. (M 40) in various percentages (i.e. FA $100 \%+$ GGBS $0 \%+$ SF $0 \%+$ MK $0 \%$, FA $70 \%+$ GGBS $20 \%+$ SF $5 \%+$ MK 5\% ,FA $50 \%+$ GGBS $40 \%+$ SF $5 \%+$ MK 5\%, FA $30 \%+$ GGBS
$60 \%+$ SF $5 \%+$ MK 5\%, FA $10 \%+$ GGBS $80 \%+$ SF $5 \%+$ MK 5\%, ) with constant molarity (i.e.8M).

\section{REVIEW OF LITERATURE}

Davidovits et al. (1990) studied the environmental effects including temperature on geopolymer concrete.

Polomo et al (1999) studied the properties of alkaliactivated fly ashes.

Cheng and Chiu et al (2003) reported the study of making fire- resistant geopolymer using granulated blast furnace slag combined with metakaolinite. The combination of potassium hydroxide and sodium silicate was used as alkaline liquids. Among the waste or by-product materials, fly ash and slag are the most potential source of geopolymer. Several studies have been reported related to the use of these source materials

Harjidto et al (2005) tested and gave mechanical properties of geopolymer cement and concretes. The results are good

Wallah et al (2005) reported the results on the long term properties of geopolymer (fly ash based) concrete.

Lloyd et al (2009) have studied the durability properties of GPC and reported better results.

Vijay.k et al (2012) studied the properties of glass fiber reinforced GPC and reported the strength results.

Sonal p.takkar et al (2014) discussed about the various combinations of GGBS and Flyash as source material, to produce geopolymer concrete at ambient temperature. It has been generally accepted that heat treatment is required for producing geopolymer concrete which is considered as draw back affecting its applications

Sarath Chandra Kumar.B et al. (2016) reported the following conclusions based on his work the Workability of geopolymer concrete decreased as the metakaolin content increases with GGBS. But increase in GGBS does not affect the workability. Mechanical properties such as compressive strength split tensile strength and flexural strength shows increasing trend with the addition of metakaolin. Mix with $50 \%$ of metakaolin and $50 \%$ of GGBs and seems to have good compressive split and flexural strength this may be due to increase in alkaline reaction between GGBS particles and calcium in Metakaoline.

Chandra padmakar .k et al.(2017) carried out experimental investigation on metakaoline and GGBS based geopolymer concrete from his studies it is observed that GGBS and metakaolin based geopolymer concrete has got more compressive strength when compared to normal conventional concrete.

\section{EXPERIMENTAL INVESTIGATION}

\section{Materials of GPC}

Fly ash

Fly ash is the alumino silicate source material used for the synthesis of geo-polymer binder. Low calcium class fly 
ash was obtained from APARNA RMC plant located at Miyapur. The percentage of fly ash passing through $45 \mu \mathrm{m}$ IS Sieve was found to be $95 \%$.

Ground granulated blast furnace slag

Ground granulated blast furnace slag (GGBS) is a byproduct of the steel industry. Blast furnace slag is defined as "the non-metallic product consisting essentially of calcium silicate and other bases that is developed in a molten condition simultaneously with iron in a blast furnace". The GGBS is used as a replacement to flyash by $0,20,40,60$ and 80 percents.

\section{Silica Fume}

Silica fume, also known as micro silica, is an amorphous (non-crystalline) polymorph of silicon dioxide, silica. It is an ultrafine powder collected as a by-product of the silicon and ferrosilicon alloy production and consists of spherical particles with an average particle diameter of $150 \mu \mathrm{m}$. The main field of application is as pozzolanic material for high performance concrete

\section{Metakaoline}

Metakaolin is a dehydroxylated form of the clay mineral kaolinite. Rocks that are rich in kaolinite are known as china clay or kaolin, traditionally used in the manufacture of porcelain. The particle size of metakaolin is smaller than cement particles, but not as fine as silica fume

\section{Aggregates}

The fine aggregates used in the study was river sand and coarse aggregates are crushed angular granite stone passing $12.5 \mathrm{~mm}$ sieve. The results are found to satisfy the specifications.

\section{Sodium Hydroxide}

Solution of 8 molar was prepared by mixing the pellets with distilled water. The mass of $\mathrm{NaOH}$ solids in a solution varied depending on the concentration of the solution expressed in terms of molar (M). Amount of sodium hydroxide solids are added to certain amount of water (in pellet form) to make up the solution up to 1 liter and mixed well $24 \mathrm{hrs}$ prior to usage.

\section{Sodium Silicate}

Sodium silicate solution of 8 molar was prepared by mixing the mass of $\mathrm{Na}_{2} \mathrm{SiO}_{3}$ with diluted water. Concentration of the solution expressed in terms of molar (M) and sodium silicate solution was $24 \mathrm{hrs}$ prior to usage. By combining $\mathrm{NaOH}$ with $\mathrm{Na}_{2} \mathrm{SiO}_{3}$ the polymerization reaction is activated.

Water

This is the least expensive but most important ingredient in concrete. The water, which is used for making concrete, should be clean and free from harmful impurities such as oil, alkali, acid etc. in general, the water which is fit for drinking was used for making concrete. Distilled water was preferred in the present investigation.

\section{Super Plasticizer}

Super Plasticizers are capable of reducing water content by about $30 \%$. However it is to be noted that full efficiency of super plasticizer can be obtained when it is added to a mix that has as initial slump of 20 to $30 \mathrm{~mm}$. Depending on the solid content of the mix, dosage of 1 to $2 \%$ by weight is recommend. For the present investigation, a super plasticizer namely CONPLASTSP 430 has been used for obtaining workable concrete. In addition to the above, super plasticizer And extra water are added to maintain the workability of the GPC mix

\section{DESIGN FOR GEO- POLYMER CONCRETE (GPC 40)}

The mix design procedure is adopted from the literature and based on trial as per the following steps.

1. In 1 cubic meter of concrete (mass $=2400 \mathrm{~kg}$ ), total aggregate is adopted at $78 \%$.Out of this $30 \%$ is taken as fine aggregate (River sand). The coarse aggregate consists of $60 \%$ of $20 \mathrm{~mm}$ size and $40 \%$ of 10 to $12 \mathrm{~mm}$ size.

2. In the remaining mass, the alkaline solution is $40 \%$ of the mass binder(fly ash)

3. Out of the alkaline liquid $\mathrm{NaOH}$ solution and $\mathrm{Na}_{2} \mathrm{SiO}_{3}$ solutions are mixed in the ratio of 1:2.5.

4. Solids of $\mathrm{Na}$ in the $\mathrm{NaOH}$ solution are $25.5 \%$ for molarity ' 8 '. In the $\mathrm{Na}_{2} \mathrm{SiO}_{3}$ solution the water content is $55.9 \%$.

5. From the above the total solid chemicals and water are worked out.

6. Hence finally the proportions of various constituents are worked out. Quantities required for 1 cubic meter of concrete are also shown in table 1.

Table -1 Material required for GPC (M40)

\begin{tabular}{|c|c|c|c|c|c|c|}
\hline $\begin{array}{c}\text { Sl.n } \\
\text { o }\end{array}$ & $\begin{array}{c}\text { Detai } \\
\text { ls }\end{array}$ & $\begin{array}{c}\text { Bind } \\
\text { er } \\
\text { ash }\end{array}$ & Sand & $\begin{array}{c}\text { Coarse } \\
\text { aggrega } \\
\text { te }\end{array}$ & $\begin{array}{c}\text { NaoH } \\
\text { Solutio } \\
n\end{array}$ & $\begin{array}{c}\mathrm{Na}_{2} \mathrm{Si} \\
\mathrm{O}_{3}\end{array}$ \\
\hline 1 & Ratio & 1.0 & 1.49 & 3.47 & 0.114 & 0.286 \\
\hline 2 & $\begin{array}{c}\text { mass } \\
\text { es for } \\
1 \\
\text { cubic } \\
\text { meter } \\
\text { of } \\
\text { GPC }\end{array}$ & $\begin{array}{l}377.1 \\
4\end{array}$ & 661.1 & 1310.40 & 43.102 & 107.7 \\
& & & & 5 & \\
\hline
\end{tabular}

Mix combinations tried in the present investigation Five basic combinations between fly ash, GGBS, Silica fume, and Metakaoline were tried. The combinations were obtained by replacing fly ash with GGBS by $0 \%, 20 \%$, $40 \%, 60 \%, 80 \%$ along with constant $5 \%$ replacement of silica fume and metakaoline. These combinations of GPC were tested for compressive strength, split tensile strength and flexural strength properties at the age of 7, 14, 28, 45 days in ambient curing. 


\section{Mixing and Casting}

The various materials of GPC like fly ash, GGBS, silica fume, metakaoline, Coarse aggregate, fine aggregate, super plasticizer have been weighed accurately as per the mix proportions. The alkaline solution $\left(\mathrm{NaOH}+\mathrm{Na}_{2} \mathrm{SiO}_{3}\right)$ is made ready by one day earlier to mixing. A dry mix with all the ingredients is prepared in the pan mixer. The alkaline solution is added and mixed. Super plasticizer is added to maintain workability. Sufficient number of cubes, cylinder and beam specimens were cast for testing for compressive strength, split tensile strength and flexural strength.

\section{Curing of GPC specimens}

In the present investigation, oven curing and curing at ambient temperature was adopted for GPC specimens. Demoulding of specimens was carried out two days after the casting and the specimens were subjected to curing at room temperature. Specimens were tested at the ages of 7, 14, 28 and 45 days.

\section{Workability of GPC}

While preparing the GPC mix after taking into account the quantity of water available in the chemical extra water is also added to obtain a cohesive mix. If extra water being added is more the strength is adversely affected. Hence use of superplacticizer becomes necessary to obtain workability. Testing of specimens

Specimens of respective ages were tested for compressive strength, split tensile strength and flexural strength. Standard procedures were followed for testing. Average strengths are used for plotting. The variations in the compressive and split tensile strength and flexural strength are shown in fig 1 to 4 . The variations of age vs. compressive strength split tensile strength and flexural strength shown in fig 5 to 7.

\section{DISCUSSION OF THE RESUTLS}

The results of the experimental investigations are discussed herein.

\section{Mix Proportions of GPC}

In the present experimental investigations, the alkaline solution is taken as $40 \%$ of the binder (fly ash, GGBS, silica fume and metakaoline). In the alkaline solution $\mathrm{NaOH}$ of molarity 8 was taken as $28.5 \%$ of the total. The remaining is $\mathrm{Na}_{2} \mathrm{SiO}_{3}$. The ratio of water to binder (fly ash, GGBS, silica fume, and metakaoline) is 0.21 with these proportions GPC equivalent to Grade 40 is evolved.

\section{Design strength of GPC}

It can be seen from the results (fig 1, 2\& 5) that the compressive strength increases with age of the specimens. The GPC specimens have exhibited almost the design strength at the age of 28 days. This validates the design method used in the present investigation. The compressive strength increases with age and the highest strength is obtained at 45 days showing an increase of nearly 12 to $15 \%$. This may be due to the fly ash binder which reacts slowly. Replacement of fly ash with GGBS has yielded more strength with $80 \%$ replacement giving highest strength.

\section{Split tensile strength results}

It can be observed from the results (fig 3\&6) the results of split tensile strength follow the same pattern as the compressive strength. The strength increases with age. Presence of GGBS has contributed to increase in the split tensile strength. The split tensile strength has increased from 2.6 Mpa to 9.4 Mpa when the GGBS is increased. Hence it is clear that GGBS plays a key role in the design strength of GPC mix with maintaining constant rate of Metakaolin and micro silica proportion.

\section{Flexural strength results}

It can be observed from the results (fig $4 \& 7$ ) the flexural strength of GPC with Fly ash, Metakaolin, micro silica as binder after 7,14,28 and 45 days of ambient curing with same 8 molarity as the GGBS of the mix is increased, and the flexure strength has increased from 4.5 Mpa to13.5 Mpa when the GGBS is increased. Hence it is clear that GGBS plays a key role in the design strength of GPC mix.

\section{Presence of GGBS in the GPC mix}

The result (fig 1 to 7) clearly show that the replacement of fly ash with GGBS by $0 \%, 20 \%, 40 \%, 60 \%, 80 \%$ along with constant $5 \%$ replacement of silica fume and metakaoline as binder in the GPC mix has contributed to strength increase. In the present investigation, the maximum increase was recorded with $80 \%$ replacement.

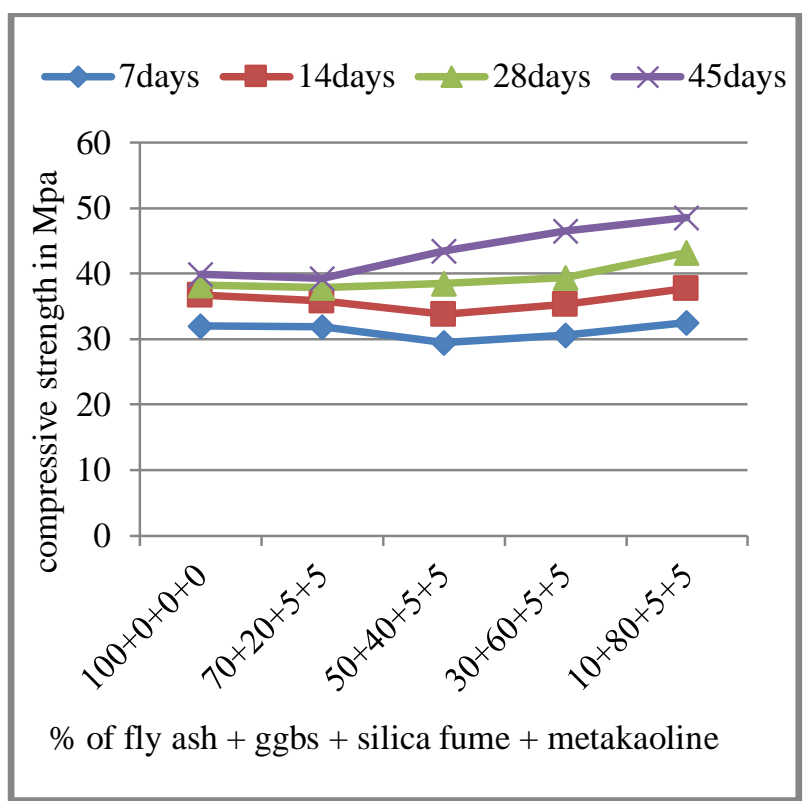


Fig. 1. \% of fly ash+ggbs+micro silica + metakaoline Vs Compressive strength

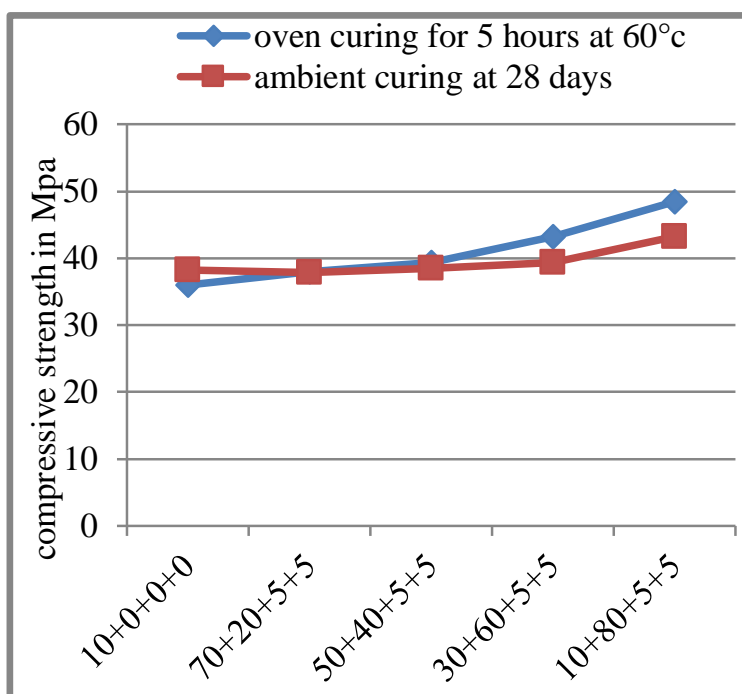

$\%$ of fly ash + ggbs + silica fume + metakaoline

Fig. 2. $\%$ of fly ash+ggbs+micro silica + metakaoline Vs Compressive strength of oven and ambient curing

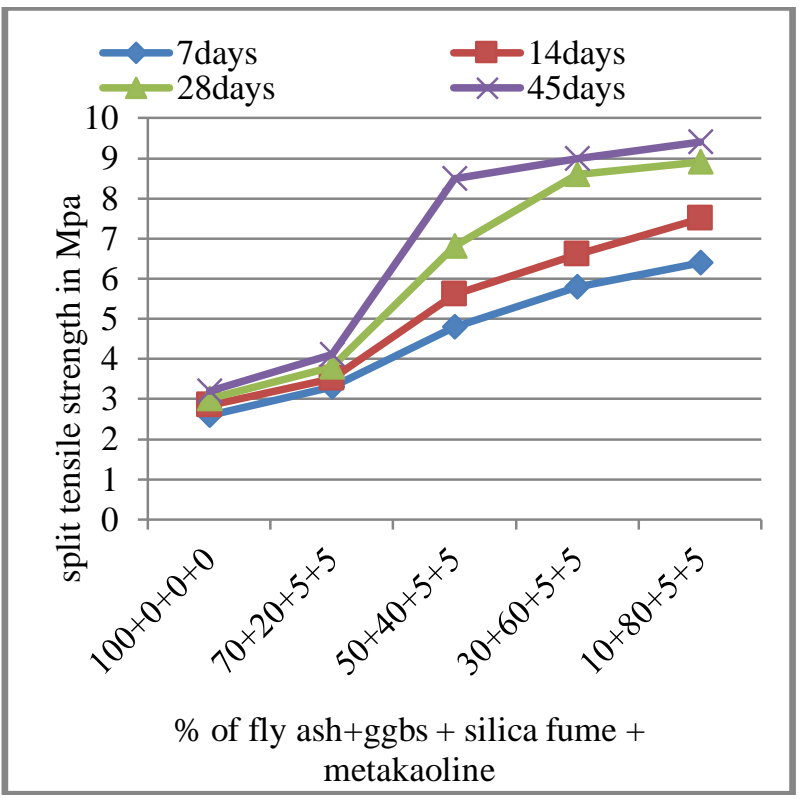

Fig. 3. \% of fly ash+ggbs+micro silica + metakaoline Vs split tensile strength

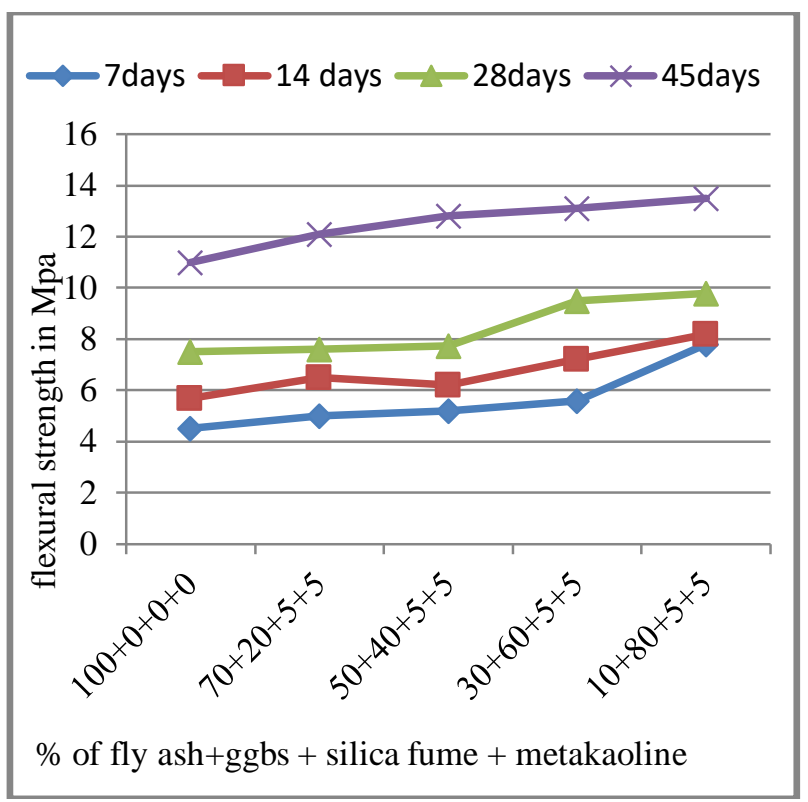

Fig 4. $\%$ of (fly ash+ggbs+micro silica + metakaoline) Vs Flexural strength

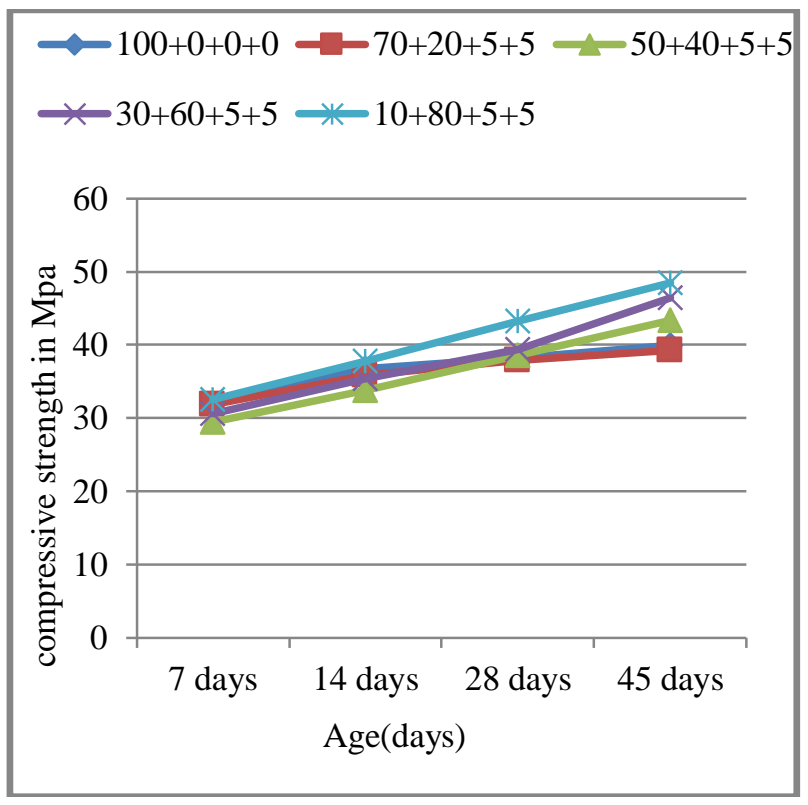

Fig. 5. Age Vs Compressive Strength 


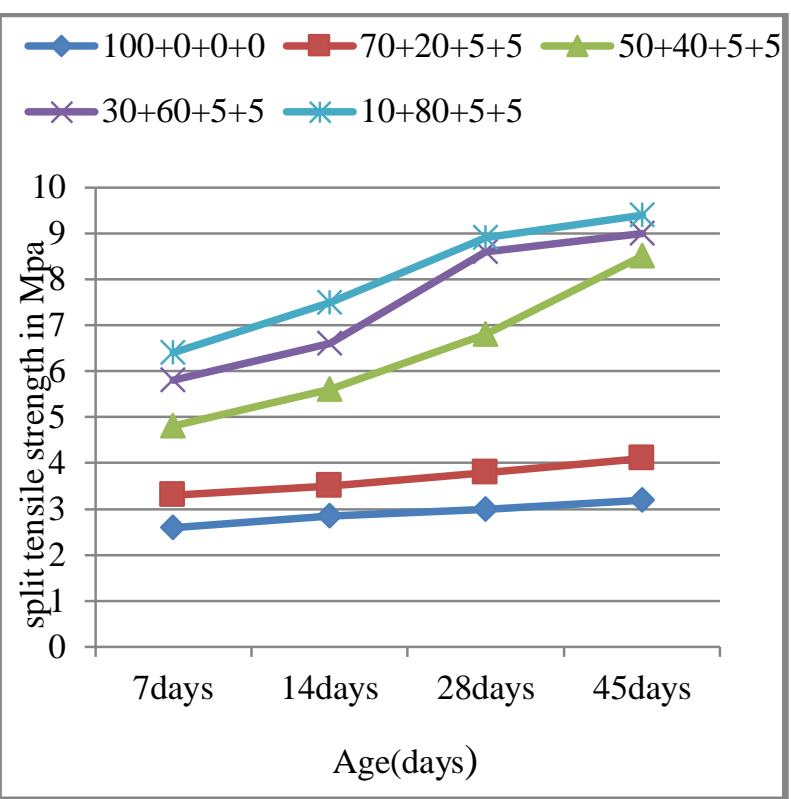

Fig. 6. Age Vs Split tensile Strength

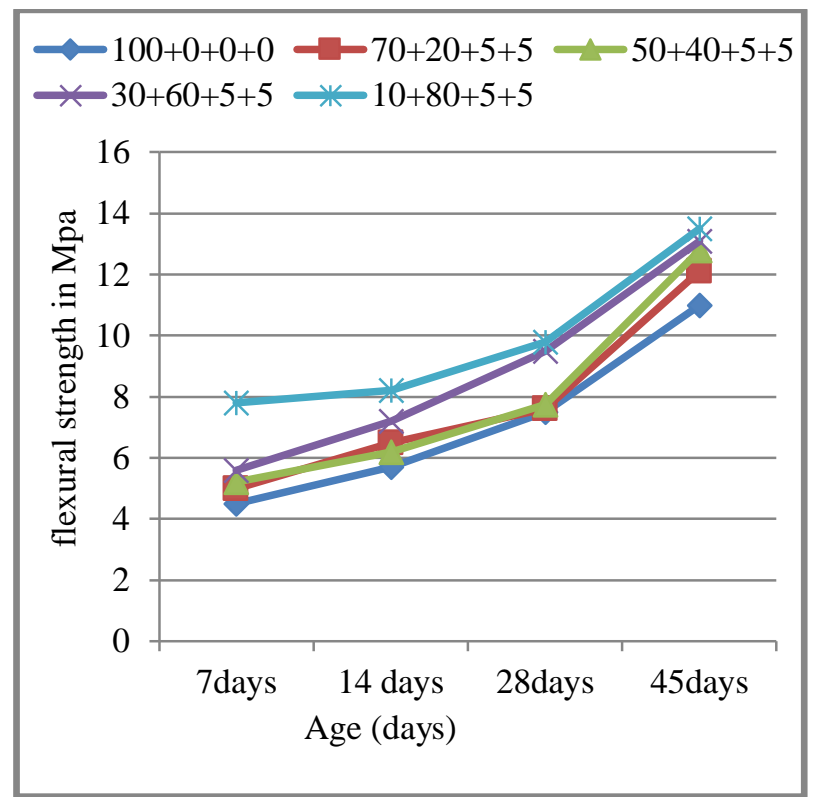

Fig. 7. Age Vs Flexural Strength

\section{Influence of ambient curing}

Ambient curing at room temperature instead of oven curing was adopted in the present investigation. Ambient curing over a period of 28 days has resulted in the design strength of GPC. It can be seen that by extending the period of ambient curing the 28 days strength has increased by nearly $15 \%$ at the age of 45 days for the basic GPC mix. Hence, it is clear that extended curing period contributes to increase in the strength because of the fly ash binder with slow reactivity.

\section{Overall comments}

Optimum GPC mixes can be developed with tertiary mixes like fly ash, GGBS, silica fume, metakaoline and by using alkali activated solution.

\section{CONCLUSIONS}

Based on the experimented investigation, the following conclusions are drawn.

1. By varying the relative properties of $\mathrm{NaOH}$ of molarity 8 GPC (40) can be obtained with binder to chemical solution ratio of 0.21 .

2. To maintain workability of GPC the required percentage of super plasticizer may be added to the mix.

3. By curing at ambient temperature over 28 days the required design strength can be obtained. Extended curing periods give increased strength.

4. The compressive strength has increased from $36 \mathrm{~N} / \mathrm{mm}^{2}$ to $48 \mathrm{~N} / \mathrm{mm}^{2}$ when the GGBS is increased. Hence it is clear that GGBS plays a key role in the design strength of geopolymer concrete mix.

5. The split tensile strength has increased from $2.6 \mathrm{~N} / \mathrm{mm}^{2}$ to $9.4 \mathrm{~N} / \mathrm{mm}^{2}$ when the ggbs percentage is increased. Hence it is clear that ggbs plays a key role in the design strength of geopolymer concrete mix while maintaining constant rate of metakaolin and micro silica proportion.

6. The flexural strength has increased from $4.5 \mathrm{~N} / \mathrm{mm}^{2}$ to $13.5 \mathrm{~N} / \mathrm{mm}^{2}$ when the ggbs is increased.

7. Among the various combinations tried in this investigation, the combination with $10 \%$ fly ash $+80 \%$ GGBS $+5 \%$ silica fume $+5 \%$ metakaolin has been found to be optimum.

8. Though the initial cost of GPC is high because of chemicals, there is saving in water curing. GPC is more impervious, chemical resistant and crack free. As such, geo polymer concrete works out to be economical

\section{ACKNOWLEDGMENTS}

The authors thank the authorities of Methodist College of Engineering for the encouragement and the facilities provided for conducting the present research investigation.

\section{REFERENCES}

1. Davidovits, J. Comrie, DC. Paterson, JH. Ritcey, DJ.(1990) "Geopolymer concretes for environmental protection"- Concrete International : Design and construction, vol.12(7), (pp. 30-40)

2. Ferria, JG. Branco, FA. (2011). "GRC mechanical properties for structural applications."Institute Superior Technico, A.V. Rovisco Pias, 1049-001 Lisbon, Portugal,( pp.1147-1156) 
3. Hardjito, D. and Rangan, B.V. (2005) "Development and properties of low-calcium fly-ash based Geo polymer concrete"- Research Report GC 1, Curtin University of Technology, Perth, Australia.

4. Hardjito, D.Wallah, S. Sumajouw, M. and Rangan.B.V (2005). "Fly ash based geopolymer concrete."Australian Journal of Structural Engineering, vol.6(1),( pp.77-85)

5. Lloyd, N.A. Rangan, B.V. (2009) "Durability of Geopolymer Concrete Box Culverts-A Green Alternative", Proceedings of the 34th Conference on our world in concrete structures, Aug 16 2009, (pp. 85-92). Singapore: CI Premier Pty Ltd.

6. Palomo, A. Grutzeck, M. W. Blanco, M.T. (1999). "Alkali-Activated Fly Ashes, A Cement for the future."Cement and Concrete Research vol.29 (8), (pp1323-1329).

7. Rangan, B.V. (2008) "Low-Calcium Fly Ash-Based Geopolymer Concrete" Chapter 26, Concrete Construction Engineering Handbook, Second Edition, Editor-in-Chief: E.G. Nawy, CRC Press, New York, 2008,(pp. 26.1-26.20); also available as Research Report GC4, Curtin University of Technology.

8. Vijai, K. Kumutha, R. Vishnuram BG (2012). "Properties of glass fiber reinforced Geo polymer Concrete composites, "Asian J.Civil Engg(Build House) 13(4),( pp.511-520)

9. Vijai, K. Kumutha, R. and Vishnuram, B.G (2012), "Investigation on properties of glass fiber reinforced fly ash based Geopolymer concrete", International Journal of earth science and engineering Vol 5, no 4,( pp. 817-824)
10. Rajamane, N.P. Nataraja, M.C. and jeyalakshmi, R. (2014) pozzolanic industrial waste based geopolymer concretes with low carbon foot print", ICJ, vol. 88(7), (pp.49-68).

11. Rohit zende, Mamatha, A. (2015) "study on flyash and GGBS based geopolymer concrete under ambient curing" JETIR, vol.2 (7), (pp.3082-3087).

12. vijaya Rangan, B. (2014) "Geopolymer concrete for environmental protection” ICJ, vol.88(4) , (pp.41-48,5059)

13. Manoj Kumar, N. Hanitha, P. (2016) "Geopolymer Concrete by using fly ash and GGBS as a replacement of cement", IOSR-JMCE, vol. 13(6), (pp.85-92).

14. Sonal P Thakkar, Darpan J Bhorwani, Rajesh Ambaliya, (2014) "Geopolymer concrete using different source materials" IJETAE, vol. 4, (pp.10-16).

15. Sarath Chandra Kumar, B. And Ramesh, K. (2016) "Experimental Study on Strength Properties of Metakaolin and Ggbs Based Geopolymer Concrete" ARPN Journal of Engineering and Applied Sciences, vol.11 (21), (pp.12414-12422).

16. Chandra Padmakar, K. And Sarath Chandra Kumar, B. (2017) "An Experimental Study On Metakaolin And Ggbs Based Geopolymer Concrete" International Journal of Civil Engineering and Technology (IJCIET) Volume 8, Issue 1, January 2017, (pp. 544-557)

17. Ta-Wui Cheng and Chiu, J.P. (2004) "Fire-resistant geopolymer produce by granulated blast furnace slag" Minerals Engineering, vol.16 (3), (pp.205-210). 